\title{
Removal of methylene blue from aqueous solutions using Luffa adsorbent modified with sodium dodecyl sulfate anionic surfactant
}

\author{
Abbasi H.* and Asgari H. \\ Quality Control Expert, Pakshoo Industrial Group, Qazvin, Iran \\ Received: 19/04/2018, Accepted: 18/10/2018, Available online: 25/10/2018 \\ *to whom all correspondence should be addressed: e-mail: Hamed.abbasi1992@gmail.com
}

https://doi.org/10.30955/gnj.002722

\section{Abstract}

Methylene blue is one of the most widely used dyes in various industries such as textiles and dyeing which, due to toxicity, causes several environmental problems as well as difficulties in wastewater treatment process. Therefore, many studies have been carried out on the removal of the dye from industrial wastewater and aqueous solutions using various adsorbents. In the present study, a Luffa adsorbent surface was first modified by sodium dodecyl sulfate anionic surfactant and then methylene blue dye removal from aqueous solution was studied under various operating conditions in batch experiments. The parameters addressed included of the dye solution $\mathrm{pH}$, adsorbent amount, initial methylene blue concentration in the dye medium, and the duration of adsorption. The use of anionic surfactant changed the adsorbent surface charge and thus increasing absorbent ion exchange capacity. The results showed that the highest removal efficiency occurs in mediums with an initial concentration of $50 \mathrm{mg} \mathrm{L}^{-1}$ and $\mathrm{pH} 6-9$, where $99 \%$ of the dye was removed from the medium using $1 \mathrm{gr}$ modified adsorbent in 60 minutes. Since the obtained $\mathrm{pH}$ range covered the neutral and near neutral media, the adsorbent can be used in a variety of industries. Finally, the dye adsorption process was modeled and examining the adsorption isotherms, it was observed that the empirical data appropriately followed the Freundlich model.

Keywords: Anionic surfactant, Luffa L20, methylene blue, isotherm, removal efficiency.

\section{Introduction}

The presence of dye compounds in industrial wastewater and water resources, the negative environmental consequences, and the effects on the health of individuals, plants and aquatic animals has always been a challenge in wastewater treatment (Mondal et al., 2018). Methylene blue, which is known as a polar organic water soluble material (Mahmood et al., 2013), is a toxic compound that can cause respiratory disease and eye damage (Ponnusami et al., 2008). The difficulty of removing synthetic dyes from wastewater and aqueous solutions has led to the development of strict environmental laws (Pearce et al., 2003). Hence, extensive efforts have been made to remove this compound from aquatic solutions and industrial wastewaters. Several methods have been used to remove dye compounds, but the high efficiency dye compounds removal using adsorbents, has made adsorption into one of the most ideal methods (Ramakrishna and Viraraghavan, 1997). One of the most commonly used methods for dye removal is biological removal and activated carbon adsorption; however, recently the use of biodegradable adsorbents and adsorbents from agricultural waste has also been considered frequently (Crini, 2006). For example, Kannan et al. reviewed the kinetics and methylene blue adsorption mechanism with carbon activators obtained from materials such as rice stems, bamboo skin and coconut shell. The results increased dye removal efficiency with adsorption particles size reduction, initial methylene blue concentration, and increase in the medium $\mathrm{pH}$, the absorbent amount, and contact time (Kannan and Sundaram, 2001). Singh et al. investigated dye adsorption from wastewater using sugar cane stem powder. The results showed that optimal conditions occur by absorbent particle size decrease, the initial dye concentration, and adsorption $\mathrm{pH}$ and temperature at 7.5 and $25^{\circ} \mathrm{C}$, respectively. Interestingly, as the dye concentration increased from $6 \mathrm{mg} \mathrm{L}^{-1}$ to $12 \mathrm{mg} \mathrm{L}^{-1}$, the removal percentage of methylene blue dye was reduced from 90.78 to $78.02 \%$ (Singh and Khattri, 1999). Also, the kinetics of removing methylene blue from salty media was studied using pine fruit. It was observed that with the increase in salt concentration in the dye medium, the amount of adsorption decreased. Further, dye removal was also in perfect agreement with the Langmuir model (Sen et al., 2011). In another study, activated carbon adsorbent was prepared by sawdust and adsorption was recommended at $\mathrm{pH} 3$ or lower (Malik, 2004). Namasivayam et al. investigated red Congo dye removal by coconut outer shell and suggested environment acidity contributes to absorb the dye 
(Namasivayam and Kavitha, 2002). In a study on malachite green dye removal by Garg et al. using modified sawdust, it was observed that the sulfuric-acid-modified adsorbent had better adsorption capacity than formaldehydemodified adsorbent and both adsorbents had the best performance at pH 6-9 media (Garg et al., 2003). The same corrective action was performed on acacia wood where pH 7 was proposed as optimal (Gong et al., 2005). In the recent years, other studies have also been carried out on the dye removal using other adsorbents and available techniques. For example, the crystal violet removal from wastewater using SDS-modified alumina yielded 99\% dye removal (Adak et al., 2005). In 2017, George Z. Kyzas et al. studied dye removal using Graphene composites as adsorbents. It was observed that adsorption capacity of graphene composites can reach up to $1300 \mathrm{mg} / \mathrm{g}$ depending on the dye molecule (Kyzas et al., 2018). Also, dye removal from aqueous solutions using other adsorbents such as ash and bentonite, volcanic glass, magnesium chloride (Hu et al., 2006; Doğan et al., 2000; Gao et al., 2007), and graphene oxide (Yang et al., 2011; Zhang et al., 2011; Song et al., 2015) has been studied. In addition to adsorption, other methods such as ultrafiltration, nanofiltration, electrocoagulation (Purkait et al., 2004; Mondal et al., 2018), and positive plasma use (Ikoma et al., 2012) have been used for dye removal.

Luffa is a cellulosic compound known as a suitable adsorbent for porous structure, low density, and high adsorption capacity. As a natural adsorbent, Luffa does not have the environmental problems associated with synthetic adsorbents (Baharlouei et al., 2017; Shen et al., 2012).

\subsection{Novelty}

Previous studies are mostly based on the modification of synthetic adsorbents. In the present study, a natural adsorbent is used to remove dye from aqueous solutions to reduce the cost of synthesizing synthetic adsorbents. Natural adsorbents often have low absorption capacity. The combination of Luffa with an anionic surfactant can increase the removal of Methylene Blue. It has also been shown that the use of a larger amount of adsorbent does not necessarily increase absorption capacity.

\section{Materials and methods}

The equipment and materials used in this research include:

Methylene blue dye made by Panreac Spain, Luffa fibers (Luffa L20) by French Lessonia, Sodium Dodecyl Sulfate with $90 \%$ purity made by Merck Germany, $\mathrm{NaOH}$ (0.1 mol $\left.\mathrm{L}^{-1}\right)$ and $\mathrm{HCl}\left(0.1 \mathrm{~mol} \mathrm{~L}^{-1}\right)$ by Merck, Spectrophotometer Model 6850 made by JENWAY UK, incubator with shaker (Labcon), centrifuge model EBA20 by Hettich Germany, electric oven model UN11z by Memmert Germany, the $\mathrm{pH}$ meter model 827 manufactured by Metrohm, Switzerland.

Methylene blue specifications:

The specifications and characteristics of the methylene blue used in this study are presented in Table 1 (Pathania et al., 2017; Bao and Zhang, 2011):
Table 1. Chemical properties of methylene blue

\begin{tabular}{cc}
\hline & \\
\hline Chemical name & $\mathrm{C}_{16} \mathrm{H}_{18} \mathrm{ClN}_{3} \mathrm{~S}$ \\
\hline Chemical formula & $180^{\circ} \mathrm{C}$ \\
\hline Melting point & $50 \mathrm{~g} \mathrm{~L}^{-1}\left(\mathrm{H}_{2} \mathrm{O}\right)$ \\
\hline Solubility $\left(@ 20^{\circ} \mathrm{C}\right)$ & $660-665 \mathrm{~nm}^{-}$ \\
\hline$\lambda_{\max }$ & $319.86 \mathrm{~g} \mathrm{~mol}^{-1}$ \\
\hline $\mathrm{Mw}$ &
\end{tabular}

Anionic surfactant specifications:

The anionic surfactant specifications and chemical structure used to modify the Luffa particles are given in Table 2:

Table 2. Anionic surfactant specification used to modify the Luffa adsorbent structure

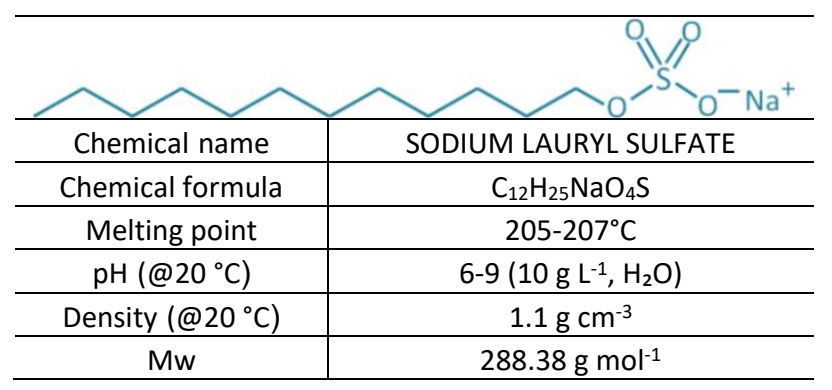

Initially, methylene blue stocks solution was prepared at a concentration of $2000 \mathrm{mg} \mathrm{L}^{-1}$. Then, to calibrate the spectrophotometer, solutions with different concentrations (2-250 mg L-1) of methylene blue were prepared using the stocks solution. Calibration curve was plotted using Microsoft Excel program based on the absorbance for each solution at the maximum adsorption time (Moffett, 2010).

The Luffa L20 particles were in the form of 40-80 mesh fibers, which were first washed with distilled water several times and then placed in an oven at $105^{\circ} \mathrm{C}$ for two hours to remove moisture. To prevent moisture adsorption, Luffa particles were transferred to the desiccator and stored. To improve dye adsorption, Luffa particles were modified by an anionic surfactant. Accordingly, the sodium lauryl sulfate $10 \%$ solution was first prepared. This solution is an anionic surfactant, which can be used to absorb cationic compounds such as methylene blue. Luffa particles were placed in contact with sodium lauryl sulfate solution $10 \%$ for 2 hours at 300 rpm, so that the surface structure of the material was modified and would have anionic surface charge. The Luffa particles were then rinsed with distilled water several times and dried at $105^{\circ} \mathrm{C}$ for 4 hours in the oven before being moving to the desiccator.

In this study, the effects of solution $\mathrm{pH}$, adsorbent content, initial methylene blue concentration, and adsorbent-dye solution contact duration were studied under batch conditions. 
Table 3. Effective parameters in adsorption of methylene blue by Luffa $L 20$ modified adsorbent

\begin{tabular}{ccccc}
\hline Parameters & Contact time $(\mathbf{m i n})$ & $\begin{array}{c}\text { Initial concentration of } \\
\text { methylene blue }\left(\mathbf{m g ~ L}^{-1}\right)\end{array}$ & Adsorbent dosage (mg) & pH \\
\hline Levels & $20,60,90,100,120,240$ & $2,10,50,100,200$ & $0.25,0.5,1,1.5,2,2.5$ & $3,6,7,9,12$ \\
\hline
\end{tabular}

In each experiment, $100 \mathrm{cc}$ of dye solutions at required concentration was prepared from stocks solution. All experiments were carried out in a shaker incubator at $25^{\circ} \mathrm{C}$ and $115 \mathrm{rpm}$ to provide the required conditions for methylene blue dye adsorption such as temperature and adsorbent rate and dye solution mix. To separate suspended particles, after each test the dye solutions were transferred to the test tube and centrifuged for 3 minutes at $3000 \mathrm{rpm}$. Then, to determine the methylene blue concentration at dye medium, the absorbance of each dye solution at its maximum absorption wavelength $(664 \mathrm{~nm})$ was measured by spectrophotometer. Then, according to the calibration curve, the final concentration of methylene blue was obtained after adsorption. To ensure the repeatability of the results, each test was repeated twice.

Equations (1) and (2) were used to calculate the removal percentage of dye and adsorption capacity (Marr et al., 1973; National Center for Biotechnology Information, 2018).

$$
\begin{aligned}
& q_{e}=\frac{\left(C_{0}-C_{e}\right) V}{m} \\
& \%=\frac{\left(C_{0}-C_{f}\right)}{C_{0}}
\end{aligned}
$$

Where, $\mathrm{q}_{\mathrm{e}}$ is adsorption capacity $\left(\mathrm{mg} \mathrm{g}^{-1}\right) ; \mathrm{C}_{0}$ is the initial concentration of methylene blue $\left(\mathrm{mg} \mathrm{L}^{-1}\right) ; \mathrm{C}_{e}$ is the equilibrium dye concentration $\left(\mathrm{mg} \mathrm{L}^{-1}\right) ; \mathrm{C}_{f}$ is the final concentration ( $\mathrm{mg} \mathrm{L}^{-1}$ ); $\mathrm{V}$ is the volume of the dye solution (L) and $\mathrm{m}$ is the adsorbent mass (gr).

\section{Analysis results}

In this section, the effect of adsorbent surface modification by sodium dodecyl sulfate anionic surfactant on the removal of methylene blue from aqueous solutions is presented and then the effects of parameters such as $\mathrm{pH}$, initial dye concentration, adsorbent amount, adsorbent-dye solution contact duration on methylene blue removal and adsorption capacity of the adsorbent were investigated.

The removal percentage of methylene blue using modified Luffa L20 and unmodified Luffa is shown in Figure 1. The results indicate that modifying Luffa by anionic surfactant, the percentage of dye removal was increased by $9 \%$ after $0.25 \mathrm{~g}$ of adsorbent was applied and by $1.5 \%$ after applying $2.5 \mathrm{~g}$ adsorbent. The difference was decreased by increasing the amount of adsorbent and saturation of the medium by adsorbent. In fact, when negatively charged by an anionic surfactant, the strength and ability of Luffa to absorb methylene blue (a cationic material) increases.

\subsection{The effect of $\mathrm{pH}$ on dye removal and adsorption capacity}

In order to study the effect of $\mathrm{pH}$ on the amount of methylene blue removal, adsorption capacity, and to simulate the dye medium with industrial wastewater, dye solutions were prepared with different $\mathrm{pHs}$. Thus, the dye solutions of methylene blue were prepared with an initial concentration of $20 \mathrm{ppm}$ and $\mathrm{pH}$ values of 3, 6, 7, 9 and 12 and 0.5 grams of modified Luffa adsorbent was added to each solution. Then, the adsorption and dye concentration were measured after 60 minutes. Sodium Hydroxide $(\mathrm{NaOH})$ and $\mathrm{HCl}(0.1 \mathrm{M})$ were used to adjust the $\mathrm{pH}$ of each solution. The results are shown in Figure 1.

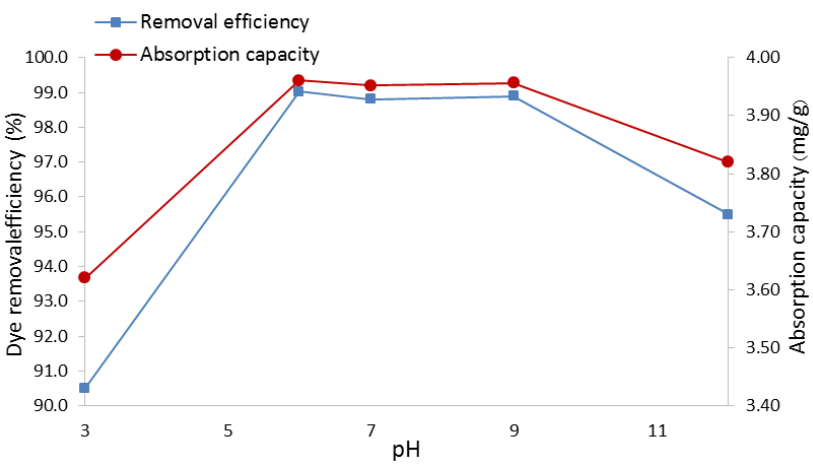

Figure 1. Effect of dye medium $\mathrm{pH}$ on the methylene blue dye removal percentage and adsorption capacity

As shown in Figure 1, as $\mathrm{pH}$ increases from 3 to 6 , the dye removal percentage and adsorption capacity increases. At low $\mathrm{pH}$ levels, the $\mathrm{H}^{+}$ions present in the medium attach to the adsorbent surface anions, neutralizing the adsorbent charge which reduces methylene blue absorption. But with increasing $\mathrm{pH}$ and reducing $\mathrm{H}^{+}$ concentrations in the medium, more anions are available to absorb dye on the surface adsorbents, and therefore, the adsorption capacity and the percentage of dye removal are increased. At 6-9 pH levels, there is little change in the adsorption capacity and the percentage of dye removal. This is because the strength of the $\mathrm{H}^{+}$and $\mathrm{OH}^{-}$groups in this range is not high enough to have a significant effect on methylene blue adsorption. In fact, at $\mathrm{pH}$ levels 6 to 7, the positive surface charge of the dye is stronger than the protons in the solution and also the adsorbent surface charge is greater than the hydroxyl groups in the dye solution at $\mathrm{pH} 7$ to 9 which results in greater tendency to absorb the dye. At $\mathrm{pH}$ values higher than 9 while increasing $\mathrm{OH}^{-}$concentration in the dye solution, the adsorption capacity is reduced and the percentage of dye removal decreases, because the $\mathrm{OH}^{-}$is attached to cationic dye particles reducing ion exchange 
capacity by neutralizing the surface charge. Therefore, the maximum capacity and the percentage of dye removal occur in the media with $\mathrm{pH}$ values of 6 to 9. Given the fact that the range covers the neutral and near-neutral media, these modified adsorbents can be used in a variety of industries that contain wastewater within this $\mathrm{pH}$ range.

\subsection{The effect of initial dye concentration on dye removal and adsorption capacity}

To investigate the effect of initial dye concentration on the methylene blue removal efficiency and the adsorption capacity, solutions of methylene blue dye were prepared with concentrations of $2,10,20,50,100,150$ and $200 \mathrm{mg} \mathrm{L}^{-1}$. The amount of $0.5 \mathrm{~g}$ of adsorbent was added to each solution and the adsorption was performed for one hour at $25^{\circ} \mathrm{C}$. In all experiments, the $\mathrm{pH}$ of the solution was adjusted to 6 . As shown in Figure 2, with an increase the initial dye concentration, the adsorption capacity increases thanks to the availability of larger amounts of dye per unit of adsorbent. By increasing dye solution concentration to $50 \mathrm{mg} \mathrm{L^{1 }}$, the dye removal efficiency increases from $98 \%$ to $99 \%$ and then with further increase in concentration, the efficiency decreases and reaches $97.5 \%$ at $200 \mathrm{mg} \mathrm{L}^{-1}$. Therefore, the highest percentage of dye removal occurs at an initial concentration of $50 \mathrm{mg} \mathrm{L}^{-1}$.

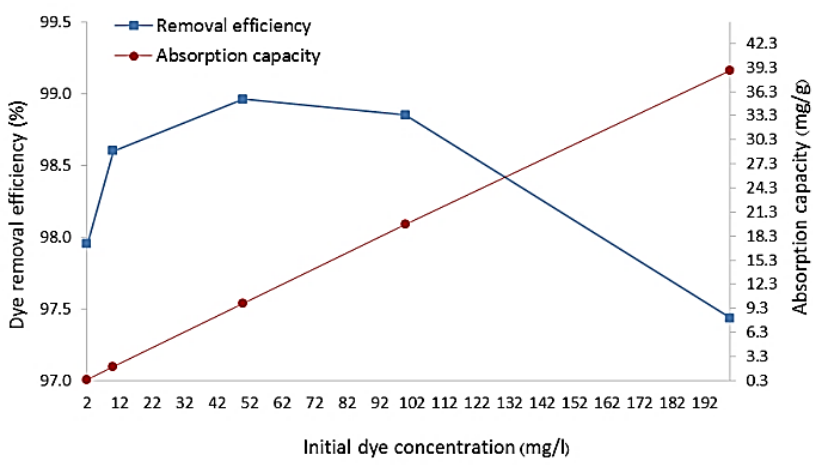

Figure 2. The effect of initial concentration of methylene blue on dye removal percentage and adsorption capacity

\subsection{Effect of adsorbent content on dye removal}

In order to study the effect of adsorbent content on dye removal, methylene blue solution $\left(20 \mathrm{mg} \mathrm{L}^{-1}\right)$ was prepared and the $\mathrm{pH}$ was adjusted to 6 . In each experiment, $100 \mathrm{cc}$ of the solution was used and a certain amount of adsorbent was added to each solution. After 60 minutes, adsorption amount and dye concentration were measured. The results are shown in Figure 3. By increasing the amount of adsorbent, the adsorption capacity had a descending rate and decreased from $7.6 \mathrm{mg} \mathrm{g}^{-1}$ (in $0.25 \mathrm{mg} \mathrm{g}^{-1}$ adsorbent) to $0.8 \mathrm{mg} \mathrm{g}^{-1}$ (in $2.5 \mathrm{mg} \mathrm{L}^{-1}$ adsorbent). Also, the highest removal efficiency occurred at the adsorbent content of $1 \mathrm{gr}$ and then, due to the saturation of the dye medium with adsorbent, and the reduced circulation of the adsorbent in this medium which consequently lead to decreased absorbent-dye contact, the percentage of dye removal dropped.

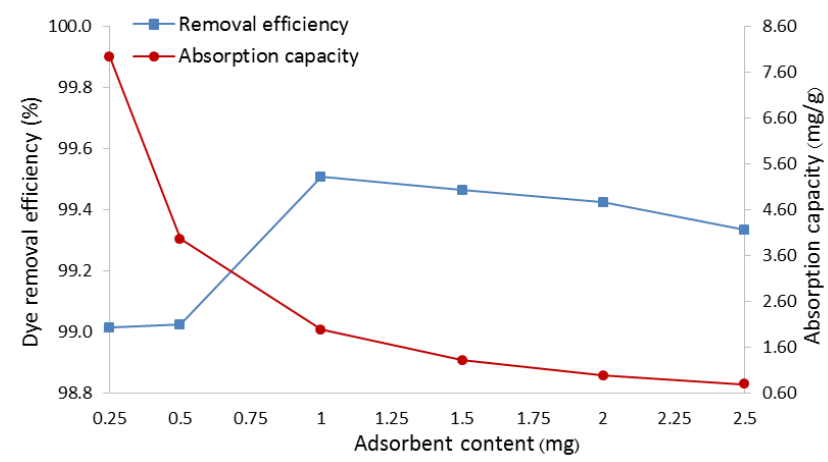

Figure 3. The effect of adsorbent dosage on adsorption capacity and removal efficiency of methylene blue

\subsection{The effect of contact time on dye removal}

The solutions used contained $20 \mathrm{mg} \mathrm{L}^{-1}$ methylene blue and with $\mathrm{pH}$ 6. For each experiment, an amount of $0.5 \mathrm{mg}$ of modified Luffa adsorbent was used and the amount of dye adsorption was measured at $25^{\circ} \mathrm{C}$ at various times. The effect of absorbent-dye solution contact time on the adsorption capacity and removal percentage of methylene blue is shown in Figure 4.

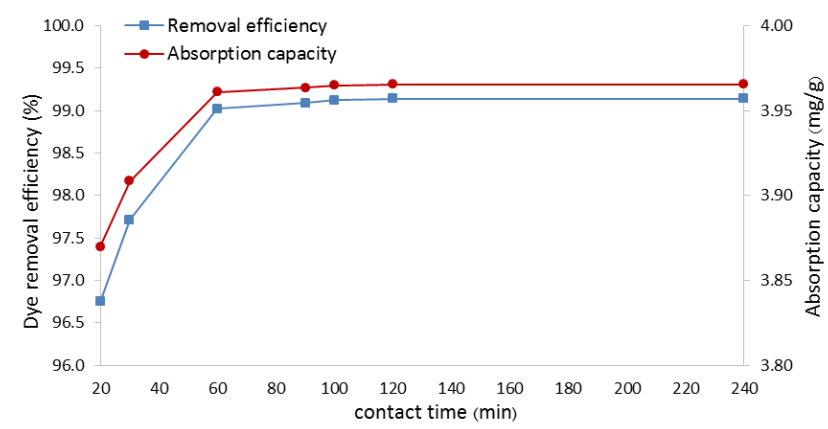

Figure 4. The effect of contact time between adsorbent and dye solution on the adsorption capacity and removal percentage of methylene blue

As it can be observed, as time elapses from 20 to 90 minutes, dye removal percentage and adsorption capacity are increased. By increasing the contact time from 60 to 90 minutes, the change in the adsorption capacity and the percentage of dye removal can be ignored for the 30 minute difference between the two time points. So, it can be claimed that after 60 minutes, equilibrium occurs in the removal of methylene blue by modified Luffa adsorbent, which quite conforms to the 99\% dye removal and adsorption capacity of $3.96 \mathrm{mg} \mathrm{g}^{-1}$.

\section{Determining the adsorption isotherm}

By determining the dye adsorption isotherm, a pattern and an equation can be derived to generalize the results and study the removal of methylene blue under other concentrations and operating conditions, thus formulating the dye removal by the modified Luffa adsorbent. 
Langmuir and Freundlich models were used to obtain the isotherm of methylene blue adsorption by the modified Luffa adsorbent. Langmuir and Freundlich models are shown in equations (3) and (4) respectively (Kiurski et al., 2012).

Langmuir equation:

$$
\frac{1}{q_{e}}=\frac{1}{q_{m}}+\frac{1}{q_{m} K_{l} C_{e}}
$$

Where, $\mathrm{q}_{\mathrm{e}}$ is the amount of absorbed dye per amount of adsorbent $\left(\mathrm{mg} \mathrm{g}^{-1}\right) ; \mathrm{q}_{\mathrm{m}}$ is the maximum dye needed for single layer formation $\left(\mathrm{mg} \mathrm{g}^{-1}\right) ; \mathrm{C}_{e}$ is the equilibrium concentration ( $\mathrm{mg} \mathrm{L}^{-1}$ ) and $\mathrm{K}_{\mathrm{I}}$ is Langmuier constant.

Freundlich equation:

$$
q_{e}=K_{f} C_{e}^{\frac{1}{n}}
$$

Where $K_{f}$ and $n$ are Langmuier constants (Appel, 1973).

Figure 5 shows the graph obtained by mapping $1 / \mathrm{q}_{\mathrm{e}}$ versus $1 / C_{e}$. It is seen that the intersection of the line is negative. Therefore, the empirical data do not match the Langmuir equation which can be due to the lack of adsorption of dye as a single layer.

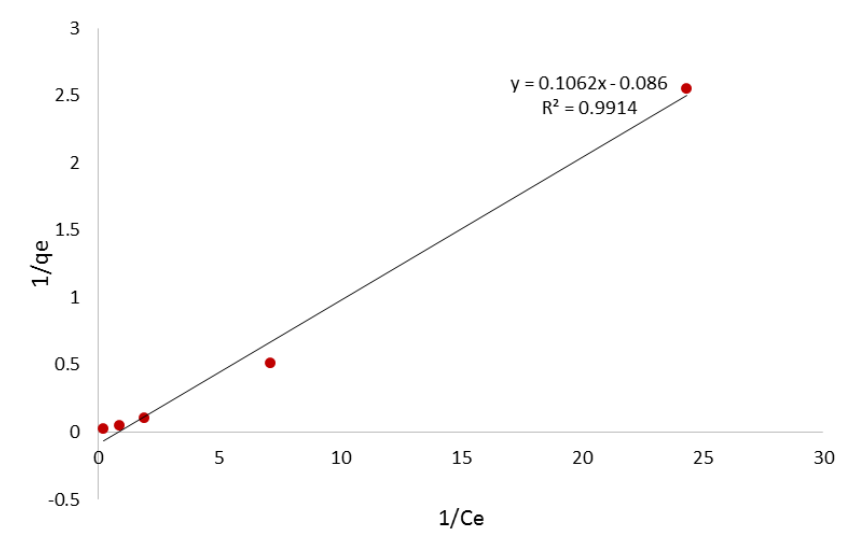

Figure 5. Mapping $1 / \mathrm{q}_{\mathrm{e}}$ versus $1 / C_{\mathrm{e}}$ (Langmuir model)

Therefore, it is better to use the Freundlich equation to obtain the isotherm. By plotting $\log q_{e}$ against $\log C_{e}$, it is possible to calculate kinetic parameters. As shown in Figure 6, the obtained data are in good agreement with the Freundlich model $\left(R^{2}=0.98\right)$. In Table 4 , the kinetic parameters of the Freundlich equation are calculated and presented.

Table 4. The kinetic parameters of Freundlich model in methylene blue adsorption with modified Luffa

\begin{tabular}{cccc}
\hline Slope & Intercept & $\mathbf{n}$ & $\mathbf{K}_{\mathbf{f}}$ \\
\hline 0.9485 & 1.069 & 1.054 & 11.72 \\
\hline
\end{tabular}

Several isotherm models such as Redlich-Peterson, Dubinin-Radushkevich,Temkin, Toth, Koble-Corrigan, Sips, Khan, Hill, Flory-Hugginsand Radke-Prausnitz have been studied by George Z Kyzas and his colleagues in 2017 and the models can be used for further research (Kyzas et al., 2017).

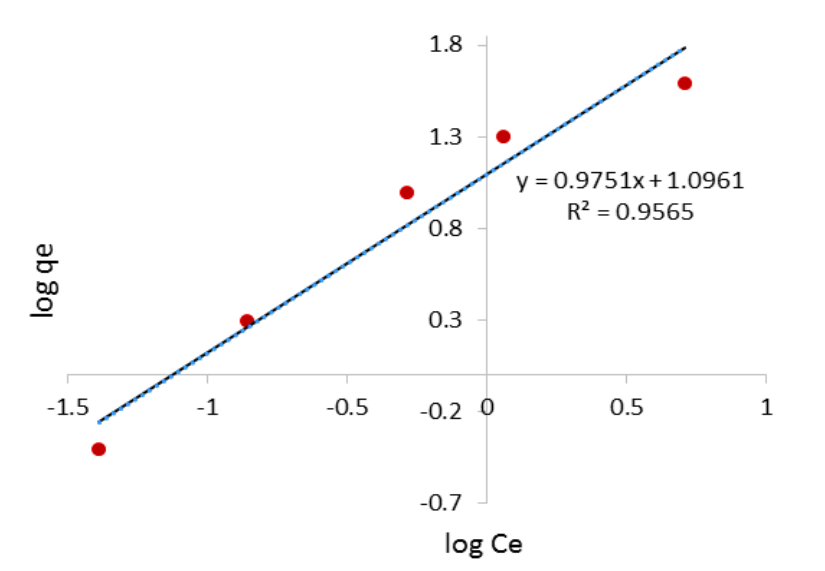

Figure 6. $\log q_{e}$ against $\log C_{e}$ and determination of kinetic parameters of Freundlich model

\section{Conclusion}

Methylene blue dye removal was performed by Luffa L20 adsorbent modified with anionic surfactant under different operating conditions. The results are as follows:

1. Luffa L20 adsorbent modification with anionic surfactant (SDS 10\%) increases the adsorption capacity and the removal efficiency of methylene blue from aqueous solution by $6 \%$.

2. The best removal efficiency and highest dye adsorption capacity are related to adsorption at $\mathrm{pH}$ levels from 6 to 9. At $\mathrm{pH}$ levels below 6 and above 9 , the removal percentage and adsorption capacity are reduced due to the effect of concentration of $\mathrm{H}^{+}$and $\mathrm{OH}^{-}$ions. Since the obtained $\mathrm{pH}$ range covered the neutral and near neutral media, the adsorbent can be used in a variety of industries.

3. The results showed that the highest dye removal percentage occurs when $1 \mathrm{~g}$ adsorbent is used where the adsorption capacity equals $5 \mathrm{mg} \mathrm{g}^{-1}$.

4. The highest dye removal efficiency was observed in a medium where the initial concentration of methylene blue was $50 \mathrm{mg} \mathrm{L}^{-1}$ where $99 \%$ of the dye was removed.

5. After a period of 60 minutes, it is possible to obtain the methylene blue removal equilibrium concentration, which given $99 \%$ dye removal, is relatively a good time in methylene blue removal.

6. The experimental data are consistent with Freundlich adsorption isotherm. However, the lack of agreement between the experimental data and Langmuir model shows that methylene 
blue dye adsorption by modified Luffa adsorbent does not occur as single-layer.

\section{Acknowledgements}

The authors thank the Quality Control unit of Pakshoo industrial group, Qazvin, Iran for providing equipment and support for this work.

\section{References}

Adak A., Bandyopadhyay M. and Pal A. (2005), Removal of crystal violet dye from wastewater by surfactant-modified alumina, Separation and Purification Technology, 44, 139-144.

Appel J. (1973), Freundlich's adsorption isotherm, Surface Science, 39, 237-244.

Baharlouei A., Jalilnejad E. and Sirousazar M. (2017), Investigation of the adsorption efficiency of methylene blue on Iranian Luffa Cylindrica: Effects of temperature and $\mathrm{pH}$, Journal of Applied Chemistry, 12, 193-212.

Bao Y. and Zhang G. (2011), Study of adsorption characteristics of methylene blue onto activated carbon made by salix psammophila. Energy Procedia, 16, 1141-1146.

Crini G. (2006), Non-conventional low-cost adsorbents for dye removal: A review, Bioresource Technology, 97, 1061-1085.

Doğan M., Alkan M. and Onganer Y. (2000), Adsorption of methylene blue from aqueous solution onto perlite, Water, Air, and Soil Pollution, 120, 229-248.

Gao B.Y., Yue Q.Y., Wang Y. and Zhou W.Z. (2007), Color removal from dye-containing wastewater by magnesium chloride, Journal of Environmental Management, 82, 167-172.

Garg V.K., Gupta R., Yadav A.B. and Kumar R. (2003), Dye removal from aqueous solution by adsorption on treated sawdust, Bioresource Technology, 89, 121-124.

Gong R., Ding Y., Li M., Yang C., Liu H. and Sun Y. (2005), Utilization of powdered peanut hull as biosorbent for removal of anionic dyes from aqueous solution, Dyes and Pigments, 64, 187-192.

Hu Q.H., Qiao S.Z., Haghseresht F., Wilson M.A. and Lu G.Q. (2006), Adsorption study for removal of basic red dye using bentonite, Industrial and Engineering Chemistry Research, 45, 733-738.

Ikoma S., Satoh K. and Itoh H. (2012), Decomposition of methylene blue in an aqueous solution using a pulseddischarge plasma at atmospheric pressure, Electrical Engineering in Japan (English Translation of Denki Gakkai Ronbunshi), 179, 1-9.

Kannan N. and Sundaram M.M. (2001), Kinetics and mechanism of removal of methylene blue by adsorption on various carbons - A comparative study, Dyes and Pigments, 51, 25-40.

Kiurski J., Adamović S., Oros I., Krstić J. and Kovačević I. (2012), Adsorption feasibility in the $\mathrm{Cr}$ (total) ions removal from waste printing developer, Global Nest Journal, 14, 18-23.

Koyuncu I. (2002), Reactive dye removal in dye/salt mixtures by nanofiltration membranes containing vinylsulphone dyes: Effects of feed concentration and cross flow velocity, Desalination, 143, 243-253.

Kyzas G.Z., Bikiaris D.N. and Mitropoulos A.C. (2017), Chitosan adsorbents for dye removal: a review. Polymer International, 66, 1800-1811.
Kyzas G.Z., Deliyanni E.A., Bikiaris D.N. and Mitropoulos A.C. (2018), Graphene composites as dye adsorbents. Chemical Engineering Research and Design, 129, 75-88.

Mahmood T., Anwer F., Mahmood I., Kishwar F. and Wahab A. (2013), Solvatochromic effect of Methylene Blue in different solvents with different polarity, European Academic Research, 1, 2286-4822.

Malik P.K. (2004), Dye removal from wastewater using activated carbon developed from sawdust: Adsorption equilibrium and kinetics, Journal of Hazardous Materials, 113, 81-88.

Marr H.E., Stewart J.M. and Chiu M.F. (1973), The crystal structure of methylene blue pentahydrate, Acta Crystallographica Section B Structural Crystallograpy and Crystal Chemistry, 29, 847-853.

Moffett J. (2010), Why calibration graphs curve in atomic absorption spectrometry, https://www.agilent.com/cs/library/applications/aa128.pdf (accessed 1 Nov 2010).

Mondal S., Purkait M.K. and De S. (2018), Introduction. In: Advances in dye removal technologies. Green Chemistry and Sustainable Technology, 1-48.

Mondal S., Purkait M.K. and De S. (2018), Nanofiltration of dyes. In: Advances in Dye Removal Technologies, Green Chemistry and Sustainable Technology, Springer, Singapore, 153-197

Namasivayam C. and Kavitha D. (2002), Removal of Congo Red from water by adsorption onto activated carbon prepared from coir pith, an agricultural solid waste, Dyes and Pigments, 54, 47-58.

National Center for Biotechnology Information. PubChem Compound Database, https://pubchem.ncbi.nlm.nih.gov/compound/6099 (accessed 9 Feb. 2018).

Pathania D., Sharma S. and Singh P. (2017), Removal of methylene blue by adsorption onto activated carbon developed from Ficus carica bast, Arabian Journal of Chemistry, 10, S1445-S1451.

Pearce C.I., Lloyd J.R. and Guthrie J.T. (2003), The removal of colour from textile wastewater using whole bacterial cells: A review, Dyes and Pigment, 58, 179-196.

Pirkarami A. and Olya M.E. (2017), Removal of dye from industrial wastewater with an emphasis on improving economic efficiency and degradation mechanism, Journal of Saudi Chemical Society, 21, S179-S186.

Ponnusami V., Madhuram R., Krithika V. and Srivastava S.N. (2008), Effects of process variables on kinetics of methylene blue sorption onto untreated guava (Psidium guajava) leaf powder: Statistical analysis, Chemical Engineering Journal, 140, 609-613.

Purkait M.K., DasGupta S. and De S. (2004), Removal of dye from wastewater using micellar-enhanced ultrafiltration and recovery of surfactant, Separation and Purification Technology, 37, 81-92.

Ramakrishna K.R. and Viraraghavan T. (1997), Dye removal using low cost adsorbents, Water Science and Technology, 36, 189-196.

Sen T.K., Afroze S. and Ang H.M. (2011), Equilibrium, kinetics and mechanism of removal of methylene blue from aqueous solution by adsorption onto pine cone biomass of Pinus radiata. Water, Air, and Soil Pollution, 218, 499-515. 
Shen J., Min Xie Y., Huang X., Zhou S. and Ruan D. (2012), Mechanical properties of luffa sponge. Journal of the Mechanical Behavior of Biomedical Materials, 15, 141-152.

Singh M.K. and Khattri S.D. (1999), Colour removal from dye wastewater using sugar cane dust as an adsorbent, Adsorption Science \& Technology, 17, 269-282.

Song S., Ma Y., Shen H., Zhang M. and Zhang Z. (2015), Removal and recycling of ppm levels of methylene blue from an aqueous solution with graphene oxide. RSC Advances, 5, 27922-27932.

Yang S.T., Chen S., Chang Y., Cao A., Liu Y. and Wang H. (2011), Removal of methylene blue from aqueous solution by graphene oxide, Journal of Colloid and Interface Science, 359, 24-29.

Zhang W., Zhou C., Zhou W., Lei A., Zhang Q., Wan Q. and Zou B. (2011), Fast and considerable adsorption of methylene blue dye onto graphene oxide, Bulletin of Environmental Contamination and Toxicology, 87, 86-90. 